\title{
Role of Women Health and Reproductive Health in women Empowerment
} Nadir Anvarbhai Dawoodani*

Chairman of Agakhan Health Service India, Jhunjhunu, Rajastan, India

\begin{abstract}
Health is state of complete physical mental and social well being and not merely the absence of disease and infirmity. The health status of women includes their mental \& social condition as affected by prevailing norms and attitudes of society in addition to their biological and physiological problems.
\end{abstract}

Keywords: Maternal mortality rate; Pregnant; Family planning; Child mortality; Anemia

\section{Objective}

1. To know the status of health in women.

2. To know the cause of disease in women.

3. To know general disease occur to women in India.

4. Cause of maternal mortality of women.

\section{Method of Research}

For research work library method and formal and informal meeting with experts are used. Primary and secondary both data are used.

The most important 'Human right' is decent standard of living, Adequate Nutrition.

Despite medical advance and technological progress, good health and well-being continue to baffle a large majority of world's population a number of birth affect on maternal mortality rate (MMR) and infant mortality rate (IMR) in India every year $8 \%$ girl become mother who are below 19 year age. Son gets frequently and promptly treatment then daughter. Abortion is a serious problem even government made law Indian food first serve to male in family then it serves to female. Sometime this leads to malnutrition.

Maternal mortality refers to death due to pregnancy related causes. The maternal mortality rate is high in India. It was 437 in 1994 in India. The causes of maternal mortality are as follows.

$\rightarrow$ Unwanted, Unplanned pregnancies

$\rightarrow$ Malnutrition high fertility

$\rightarrow$ Lack of regular medical consult

$\rightarrow$ Lack of knowledge of health care

$\rightarrow$ World's $25 \%$ of maternal mortality death occur in India \& its most of occur in rural area. Nutrition survey in India, Indicate that majority of women in India suffer from anemia and other nutrition deficiency. Most of deaths are preventable because it is only reflection of women's nutrition. In rural area health facility can not available cause the death.

Early pregnancy is a cause of maternal mortality because $50 \%$ of Indian girls married less than the legal age of marriage.

Many women become pregnant below 18 it leads to maternal mortality. And abortion is also one factor. Fertility is very high in India as compared to other developing countries. Greater frequency of birth will lead to higher mortality in rural area most of delivery take place at home and not in the hospital. The umbilical cord is being cut by traditional knife and not by sterilized material. It may create infection in women and death occurs. There is no proper parental or antenatal care.

Abortion is an old as man. In 1970 a survey conducted in Mumbai hospital it is find out that $12 \%$ of girl who pass through abortion are less the 18 year age \& $92 \%$ of them are unmarried. Due to rape \& other unforeseen social \& economical circumstances leads to women abortion. Repeated abortions are leads to maternal death. The technology developed which can identify gender of child. If it's found out a girl child family force for abortion frequent abortion leads adverse effect on women health.

\section{Infant mortality}

Infant mortality means death of child below 1 year. The factors of infant mortality are age of mother, order birth genetics \& environment infant mortality rate decrease over thy year (Table 1).

\section{Child mortality}

Child mortality means death of child before 5 year for 1000 live birth. The child mortality is very high among female as compared to male children (Table 2).

\section{Son preference}

In Indian society "The birth of a male child is cause for celebration,

\begin{tabular}{|l|c|}
\hline Year & Infant Mortality Rate \\
\hline 1951 & 146 \\
\hline 1961 & 146 \\
\hline 1971 & 129 \\
\hline 1981 & 110 \\
\hline 1991 & 80 \\
\hline 2001 & 70 \\
\hline
\end{tabular}

Table 1: The infant mortality rate is very high among female children as compared to male children. Poor health care provide to female children compare to male.

*Corresponding author: Nadir Anvarbhai Dawoodani, Chairman of Agakhan Health Service India, Jhunjhunu, Rajastan, India, Tel: +918003204485; E-mail: nagyie@ymail.com

Received April 22, 2013; Accepted July 12, 2013; Published July 19, 2013

Citation: Dawoodani NA (2013) Role of Women Health and Reproductive Health in women Empowerment. J Mass Communicat Journalism 3: 157. doi:10.4172/21657912.1000157

Copyright: (C) 2013 Dawoodani NA. This is an open-access article distributed under the terms of the Creative Commons Attribution License, which permits unrestricted use, distribution, and reproduction in any medium, provided the original author and source are credited. 


\begin{tabular}{|l|c|c|}
\hline Years & Male child Mortality & Female Child Mortality \\
\hline $1979-81$ & 41 & 44.8 \\
\hline $1989-91$ & 26.3 & 29.9 \\
\hline
\end{tabular}

Table 2: There exists clear discrimination in child mortality between male \& female.

while the birth of female child is the state of commensuration son is preferred to maintain family's surname and heir to ancestral property. Strong preference for male child is reflecting in health care.

\section{Family planning acceptance}

Women bear a burden of family planning. Women use oral pill to prevent pregnancy. Oral pill create adverse effect on women health. There are two surgical method of family planning for male vasectomy. But male never allow operated on him for family planning women alone are undergoing family planning operation. Due to poverty some women are becoming victim of STD, TB, and Goiter etc. Thus women's health is affected finally leading to low sex ratio.

Female children are given less education and retained at home for help with household task. They are married at early age. So lead to high fertility result into high mortality.

\section{Food}

As per 1991 census $50 \%$ of adult women and $20.7 \%$ adolescent girl are under weight with a body mass index, low maternal height increase low birth weight especially when mother is under nourished.

If child's birth weight is less then $2.5 \mathrm{KG}$ at birth chance of dying increase $40 \%$. 50\% women are under weight which increases mortality.

According to ICMR adolescent women should intake $2224 \mathrm{~K}$ cal per day. But a reports shows that women in take 1500 to $2000 \mathrm{Kcal}$. This is less by $300-400 \mathrm{~K} \mathrm{CAL}$

\section{Iron deficiency and anemia}

Most of pregnant women and young girls are suffering from iron deficiency. The disease occurs due to iron deficiency is called Anemia. Anemia is responsible for $20 \%$ death of maternal death.

There is need for increase requirement of iron during pregnancy. Hemoglobin less then it is called anemic tablet should provide for three months. If $\mathrm{Hbl} 7$ then it is called sever anemia that women should referred to gynecologist.

\section{Depression}

Women are found to have high rate of depression and somatoform disorder affecting $33 \%$ of women. Ae estimated $5.8 \%$ of men and $9.5 \%$ of women would experience a depressive episode in any given year.

Depression is a psychological condition characterized by sadness loss of interest in activity and by decreased energy.

Virandra reported that the women who presented marital problems at family counseling centre were found to have high stress leads to depression they receive non clinical and brief counseling.

The clinical social work analysis, generally focus on linking the problems, disorder of clients. The empowerment oriented clinical social work analysis must focus on the strengths and ability of the clients that protected the clients against hardship.

The work practice with depressed women must focus on advising and assisting them to bring change in their difficult situations by external resource. The worker's dialogue with client must be base on the guidelines for empowering rather than help giving the client.

\section{Sexual Transition disease}

Early marriage, unprotect sex, unwanted pregnancies, abortion are bringing down her resistance to infection. This cause never environment to infection such as STD \& HIV.

A village level study in Maharashtra in 1989 suggests that a large portion of women are suffering from syphilis, gonaria.

APSACS estimate 5.68 million is identified as HIV positive people in India. $2 \%$ of HIV women were found in antenatal clinics.

Thus poverty, powerlessness, low social status, malnutrition, high fertility and lack of health care are resulting in high reproductive mortality among women.

\section{Social work intervention}

Mass media has to be used in communities to give information regarding STD and HIV preventive aspects of different disease should informed to women in different communities.

Programmer like adolescents education, family life education like style education should be planned \& organized exclusively for girls.

Women's organization, Mahila mandals need to be more strengthened incorporating sensitization programmers and health promotional activities for various sections.

Gender bias in mass media, education, material politics and administrative forms need to be adequately tackled by appropriate social action program. $19 \%$ of world's infant deaths occur in India. And 27 percent of all material death. Deaths of young girls in India exceed those of young boys over 300000 each year. And every sixth infant death is specifically due to discrimination of the 15 million baby girls born in India each year nearly $25 \%$ will not live to see their 15 th birthday one village level study of rural women determind on the basis of physical examination that some $92 \%$ women suffer from one or more gynecological disorder.

\section{Gender bias in health care seeking behavior}

Gender bias in health care seeking behavior is extremely pronounced $39 \%$ girls of under four year who are suffering from pneumonic were not taken to health provider or but in boy it's percentage is $29 \% .22 \%$ of female children were not given any treatment as against $17 \%$ of male children [1] (Table 3).

According to who, a maternal death is define as "The death of a women while pregnant or within 42 days of terminate of pregnancy" [2]. Maternal mortality rate MMR is expressed as a rate per 1000 live birth (Table 4).

\begin{tabular}{|l|l|}
\hline Country & MMR per $(\mathbf{4}, \mathbf{9 5 , 0 0 0 )}$ Live \\
\hline African Countries & $2,43,000$ \\
\hline America & 20,000 \\
\hline East meddle Countries & 65,000 \\
\hline European Countries & 3000 \\
\hline South East Asia & $1,43,000$ \\
\hline Western Pacific & 19,000 \\
\hline
\end{tabular}

Table 3: WHO estimates about 4, 95,000 maternal deaths occur during year 2000 globally. 
Citation: Dawoodani NA (2013) Role of Women Health and Reproductive Health in women Empowerment. J Mass Communicat Journalism 3: 157. doi:10.4172/2165-7912.1000157

Page 3 of 3

\begin{tabular}{|l|l|}
\hline Country & MMR per $\mathbf{1 0 0 0 0 0}$ Live birt \\
\hline India & 407 \\
\hline Nepal & 540 \\
\hline Bangladesh & 350 \\
\hline Sri Lanka & 60 \\
\hline China & 55 \\
\hline U.S.A. & 8 \\
\hline Japan & 8 \\
\hline Singapore & 6 \\
\hline
\end{tabular}

Table 4: MMR ratio in year 2000 was as below.

\begin{tabular}{|l|l|}
\hline State & MMR per (1, 00, 000) live \\
\hline Andhra Pradesh & 154 \\
\hline Assam & 401 \\
\hline Bihar & 451 \\
\hline Gujarat & 29 \\
\hline Haryana & 105 \\
\hline Karnataka & 195 \\
\hline Kerala & 498 \\
\hline Madhya Pradesh & 498 \\
\hline Maharashtra & 135 \\
\hline Orissa & 361 \\
\hline Punjab & 196 \\
\hline Rajasthan & 977 \\
\hline Tamil Nadu & 76 \\
\hline Utter Pradesh & 701 \\
\hline West Bengal & 264 \\
\hline
\end{tabular}

Table 5: Current MMR is 408 per 1, 00, 000 live birth and IMR 72 per 1000 live birth high.

\section{Cause of maternal death}

$80 \%$ of maternal deaths are due to direct cause that is complication of pregnancy during and after delivery. 15\% death occurs due to infection in reproductive tract [3].

\section{Social factor of maternal death}

Age at marriage, age at child birth, two close pregnancies, family size, poverty, malnutrition, illiteracy, ignorance and prejudices lack of maternal service in rural area, shortage of health man power, delivery by untrained dais, poor environmental sanitation poor communication and transport facilities, social customs are main social factor.

\section{Preventive and social measures}

To decrease maternal death following measures must be taken into consideration.

1. Early registration of pregnancy.

2. At least three antental checkup before delivery

3. Dietry supplementation including correction of anemia

4. Prevention of infection

5. Prevention of complication hypertension, diabetes, TB

6. Clean delivery practice.

7. Trained local dais.

8. Institutional delivery

9. Promotion of family plan

10. Identification of every maternal death and searching its cause

\section{State wise MMR}

Current MMR is 408 per 1, 00, 000 live birth and IMR 72 per 1000 live birth high. National socio economic goals of NPP 2000 aim to bring down MMR to 100 and IMR to 30 by 2010 (Table 5).

\section{Conclusion}

Quality of care is not time affected but a continuous process. New approaches such as primary health care are steps in right direction to reduce maternal mortality despite best antenatal care, some women may develop complication without warning signals and require emergency care round the clock maternity hospital for emergency delivery service are equally important.

\section{References}

1. Pandey A, Vir G (2010) Empowermnet of women in 21st century. Abhijit publication.

2. Goyal P (2009) Bhartiya Nari Vikasko aur. Rajathan Grnthaghar, India

3. Laxmipati R Mudanuri Women Empowerment challenges and stratagems, Regal publication. 